\title{
An Exploratory Study on Allelic Diversity for Five Genetic Loci Associated with Floral Organ Development in Rice
}

\author{
Alok Priya' ${ }^{1}$, Soumya Prakash Das ${ }^{1}$, Sayani Goswami' ${ }^{1}$, Malay Kr. Adak², Debal Deb ${ }^{3}$, \\ Narottam Dey ${ }^{*}$ \\ ${ }^{1}$ Department of Biotechnology, Visva-Bharati, Santiniketan-731235, West Bengal, India \\ ${ }^{2}$ Plant Physiology and Plant Molecular Biology Research Unit, Department of Botany, University of Kalyani, \\ Kalyani-741235, West Bengal, India \\ ${ }^{3}$ Basudha, Barrackpore, Kolkata-700120, West Bengal, India \\ Email: narottam.dey@visva-bharati.ac.in
}

Received 19 July 2015; accepted 18 August 2015; published 21 August 2015

Copyright (C) 2015 by authors and Scientific Research Publishing Inc.

This work is licensed under the Creative Commons Attribution International License (CC BY).

http://creativecommons.org/licenses/by/4.0/

c) (i) Open Access

\section{Abstract}

Allelic diversity for five genetic loci (DL, FON4, OsMADS24, OsMADS45 and Spw1) associated with floral organ development were investigated among a small heterogeneous rice population which included one wild species (O. rufipogon Griffiths), one indigenous less popular natural floral organ mutant (O. sativa var. indica cv. Jugal), one indigenous normal line (O. sativa var. indica cv. Bhutmoori) and one improved high yielding line (O. sativa var. indica cv. IR 36). Detailed spikelet morphology showed that var. Jugal had variable number $(1-3)$ of carpels within a single spikelet which was unique and resulted in variable $(1-3)$ number of kernels within a single matured spikelet (grain). The genomic DNA of each investigated line was amplified with primer sequences designed from the selected genetic loci and the derived polymorphism profiles were used for study of allelic diversity for the studied loci. The derived genetic distances among the rice lines were used for dendrogram construction. In constructed dendrogram, the mutant genotype (Jugal) showed highest similarity with the wild rice $(O$. rufipogon) instead of the rice lines. To verify this finding, the genomic DNA of each studied line was also amplified with four SSR loci, tightly linked to saltol QTL, mapped to rice chromosome 1 . The amplified products were screened for polymorphism and another dendrogram was constructed to reveal the genetic distance among the lines for selected salt tolerance linked SSR loci. In SSR derived dendrogram, the wild rice (O. rufipogon) got totally separated from the all three rice genotypes though all the studied four lines showed equal sensitivity for salt sensitivity in a physiological screening experiment. From the combined experiment, it can be concluded that genetic architecture of floral organ development loci in var. Jugal may have some uniqueness which is not present in normal rice but common to $O$. rufipogon, a species which is regarded as immediate progenitor of present day modern rice $(0$. sativa). Though

\footnotetext{
${ }^{*}$ Corresponding author.
}

How to cite this paper: Priya, A., Das, S.P., Goswami, S., Adak, M.Kr., Deb, D. and Dey, N. (2015) An Exploratory Study on Allelic Diversity for Five Genetic Loci Associated with Floral Organ Development in Rice. American Journal of Plant Sciences, 6, 1973-1980. http://dx.doi.org/10.4236/ajps.2015.612198 
this uniqueness was not confirmed by second set genetic loci associated with salt tolerance in rice, the information resulted from this experiment was preliminary and based only on allelic size (molecular weight of amplicon), which should be confirmed through sequence analysis for further analysis.

\section{Keywords}

\section{Rice, Multiple Kernel, Floral Organ Number Mutant, Rice Microsatellite, Allelic Diversity}

\section{Introduction}

The most important area in rice breeding is increase in quantity per unit area per unit time. As possibility for expanding cultivated rice land is very limited, future food security depends on a number of scientific strategies without utilizing more lands [1]. The two most significant ways are the development of hybrid and transgenic rice where the selected lines are utilized for possible inclusion of their beneficial traits/alleles into target genotypes. Indigenous and wild rice lines harbour a number of favourable genes that are not yet used in hybridization programmes and remain untapped in nature [2] [3]. Keeping this as an objective, a good number of indigenous rice landraces are being investigated to find out the different beneficial traits by a number of workers [4]-[9]. Of the different promising rice land races of South Bengal (an important rice growing region of Eastern India), Jugal (O. sativa cv. Jugal, NBPGR IC No. 567987) is an interesting and less popular indigenous line which produces one, two or even more than two kernels (seeds) per grain (spikelet) with two kernels being the majority [10] [11]. The same rice line is also available in Odisha (another rice growing state of Eastern India), where it is called as Lavkush and maintained by Central Rice Research Institute, Cuttack under the accession name JMGR. This is a unique and interesting trait, shared only by another variety, Sateen (O. sativa var. indica cv. Sateen) [11].

It is known that in normal (single-kernelled) rice, the floral meristem activity in the spikelet stops immediately after the production of single carpel (gynoecium) in the central point of apical meristems. In contrast, in Jugal, the programme for gynoecium production continues until fertilization, and further growth and development of endosperm continue thereafter, until it collectively occupies the whole space within a spikelet. Though all the endosperms within a spikelet have equal probability to develop and mature, only one or two kernels remain healthy while the rest are rudimentary and of abnormal in size and shape. This particular line was for the first time morpho-taxonomically described by Prain in 1905 from Chittagong of British India (presently in Bangladesh) and described as variety plana [12]. In an advance genetic study made by Pandian and Thiyagarajan, it was shown that mutipistilate trait in rice was controlled by mutant genes located on $6^{\text {th }}$ chromosome [13]. Genetic analysis of another multipistilate japonica rice was studied by a number of Chinese and Japanese workers [14]-[17]. It has been reported that homeotic mutation in a number of genetic loci (floral organ number, FON) causes an increased number of stamens and carpels [18] [19] in rice. Rice FON4, an orthologous to Arabidopsis $C L V 3$ caused abnormal enlargement of inflorescence meristem which ultimately developed thick culms with increased primary rachis branches and floral organs [20]. Drooping leaf $(D L)$, a member of the $Y A B B Y$ gene family, controls carpel specification and leaf midrib formation [21] and floral meristem determinacy in rice. $D L$ is an orthologue of crabs claw (CRC) of Arabidopsis and it has an antagonistic function with class B genes. The rice class B gene superwomen 1 (SPW1 or OsMADS16) is involved in stamen specification [22] [23]. SPW1 mutant is orthologue of ArabidopsisAP3 for which stamens are replaced by carpels and lodicules [24] [25]. OsMADS24 and OsMADS45 are orthologue of ArabidopsisAGL2 and AGL4 [26]. These two genes function to express the development of floral organs, and act as intermediary between meristem identity and organ identity.

The objective of this present investigation was to study the allelic diversity within the selected rice lines (cultivars Jugal, Bhutmoori, IR36) and O. rufipogon for five genetic loci (DL, FON4, OsMADS24, OsMADS45 and $S p w 1)$ linked to floral organ development in rice. The functions of these loci constitute the preliminary information required for utilization of this special trait in breeding through molecular breeding.

\section{Materials and Method}

Plant material: A total of four rice lines were studied in this study which included one wild rice, one traditional 
rice and one improved high yielding rice and one indigenous mutant line. A short description of the studied lines is presented in Table 1 .

Seeds of the studied rice lines were disinfested with sodium hypochlorite (2\%) and germinated on moist cotton kept on petriplates. Five days after germination the seedlings were transplanted to large cement tanks filled with rice field soils. The plants were maintained in natural environmental condition for further growth and development.

Morphological study of the spikelet: Young spikelets of each line were dissected under a binocular microscope and photographs were taken. Both young and mature spikelets with kernels were examined.

Study of allelic diversity for selected floral organ development loci: For study of allelic diversity five loci ( $D L$, FON4, OsMADS24, OsMADS45 and Spw1) associated with floral organ development in rice were selected. The detailed information of the selected loci is presented in Table 2 and the respective sequences for the selected genetic loci were downloaded from ensemble plant database (http://plants.ensembl.org). The primer pairs of individual loci were designed through Primer3, a free online tool to design and analyze primers for PCR amplification.

Primer sequences were subjected to BLAST analysis in NCBI database taking rice genome (IRGSP, Build 4.0) as reference to find out the possible sequence similarity in rice genome and final confirmation was done through in silico PCR targeting the respective DNA sequences using a freely available web resource (http://insilico.ehu.es). The primer sequences used to amplify these loci are given in Table 3.

Table 1. Detailed description of the studied rice lines.

\begin{tabular}{|c|c|c|c|}
\hline Acc. No. & Name of the variety & Specific trait & Source \\
\hline VB 9 & O. sativa L.var.IR 36 & $\begin{array}{l}\text { High yielding drought sensitive lines, } \\
\text { presently the popular lines of Bengal }\end{array}$ & $\begin{array}{l}\text { Central Rice Research Institute, } \\
\text { Cuttack, Odisha }\end{array}$ \\
\hline VB 18 & $\begin{array}{l}\text { O. rufipogon Griffiths } \\
\text { (popular name Redrice and } \\
\text { by some tribal as Orhidhan) }\end{array}$ & $\begin{array}{l}\text { Grow with rice in field as weeds, shatter readily } \\
\text { before harvest, so that paddy field became thoroughly } \\
\text { infested with dropped seeds, which can grow with the } \\
\text { following crop and can remain viable for } 1 \text { - } 3 \text { years. }\end{array}$ & $\begin{array}{l}\text { Collected from a low land rice field } \\
\text { in Bankura, South Bengal }\end{array}$ \\
\hline VB 156 & O. sativa L.var. Jugal & $\begin{array}{c}\text { An indigenous less popular rice lines of Bengal and } \\
\text { Odisha having } 1-3 \text { kernels within a } \\
\text { mature spikelet (grain). }\end{array}$ & $\begin{array}{l}\text { Basudha farm at Panchal, Bankura, } \\
\text { South Bengal, Central Rice Research } \\
\text { Institute, Cuttack, Odisha }\end{array}$ \\
\hline VB 162 & O. sativa L.var. Bhut Moori & $\begin{array}{l}\text { A typical drought indigenous line with } \\
\text { medium yield, used for preparation of popped rice. }\end{array}$ & $\begin{array}{l}\text { Basudha farm at Panchal, } \\
\text { Bankura, South Bengal }\end{array}$ \\
\hline
\end{tabular}

Table 2. Details of the floral organ loci with reference number used in this study.

\begin{tabular}{cccc}
\hline Gene name & Locus ID & Chromosomal location & Putative function \\
\hline FON & OS03G0215200 & $3: 6,041,346-6,048,357$ & $\begin{array}{c}\text { Homeotic transformation of carpels into stamens } \\
\text { Encoding a putative ortholog of Arabidopsis CLAVATA3 } \\
\text { regulates apical meristem size in rice }\end{array}$ \\
OsMADS25 & OS04G0304400 & $4: 13,672,710-13,675,884$ & MADS-box transcription factor 25 \\
OsMADS45 & Os08g0531700 & $8: 26,507,926-26,512,261$ & Similar to MADS-box transcription factor 7 \\
SPW1 & Os06g0712700 & $6: 30,173,627-30,177,996$ & Transcription factor, Development of lodicules and stamens \\
\hline
\end{tabular}

Table 3. Primer sequences of the studied floral organ development loci used for PCR amplification.

\begin{tabular}{ccrcr}
\hline Name of loci & Forward primer sequence & Reverse primer sequence \\
$D L$ & 5'GGGCTAGCTTGCTTGTCG3' & 5'GCGCTCCATCTGCTTG3' \\
FON4 & 5'CTCTTCTTGTGTTTGGTGGTTG3' & 5'CGCCTCATCCAGAGCAATA3' \\
OsMADS 24 & 5'AGAACAAGATCAACAGGCAGGT3' & 5'AGGCACTGCACTGTACCATACG3' \\
$S p w 1$ & 5'TCTAGCTTGGTTGGTTGGTTG3' & 5'CAACAGACACCGATAGTTTTTAAGG3' \\
\hline
\end{tabular}


The oligo sequences were synthesized from Integrated DNA Technology (IDT, USA). PCR amplification was done in a thermal cycler (M. J. Research, MC 013130) in $25 \mu \mathrm{l}$ of reaction mixture containing $100 \mathrm{ng}$ of genomic DNA, $2.5 \mu 1$ of $10 \times$ Taqbuffer, $1.0 \mu 1$ of $50 \mathrm{mM} \mathrm{MgCl} 2,0.25 \mu \mathrm{l}$ of $2.5 \mathrm{mM}$ dNTPs, $1 \mu 1$ each of the forward and reverse primers $(10 \mathrm{pmol} / \mu \mathrm{l}), 0.1 \mu \mathrm{l}$ of $5 \mathrm{U} / \mu \mathrm{l}$ Taq-polymerase. The thermal cycling profile for the first step was $95^{\circ} \mathrm{C}$ for $5 \mathrm{~min}$. For the next 35 cycles the temperature regime was $94^{\circ} \mathrm{C}$ for $1 \mathrm{~min}, 1 \mathrm{~min}$ at annealing temperature and $72^{\circ} \mathrm{C}$ for $2 \mathrm{~min}$ with final extension at $72^{\circ} \mathrm{C}$ for $10 \mathrm{~min}$. The annealing temperature of each set of PCR reaction was changed accordingly. The amplified products, obtained from the individual loci were resolved in 1.5\% agarose gel and the different allelic (variation in molecular weight) forms of each individual locus were determined. All the reagents were purchased from Fermentas Life Sciences, USA.

Study of allelic diversity for selected SSR loci linked with Saltol QTL: Genetic relationship among the four studied rice genotypes was also assessed with four previously reported tightly linked SSR loci (RM10745, RM10764, RM493, RM140) linked with Saltol QTL mapped on rice chromosome 1 [27]-[30]. The detailed information of these markers was collected from Gramene website (http://www.gramene.org), a dedicated website for plant comparative genomics. Chromosomal position of the selected loci is presented in Figure 1 and detailed primer sequences for these loci are given in Table 4.

\section{Results}

A magnified view of the dissected young spikelet revealed that in all the rice lines (except $O$. sativa cv. Jugal) and also in $O$. rufipogon, the reproductive unit of spikelet contains six stamens, and one carpel with bifid stigma. In the spikelets of Jugal, however, the number of carpels vary from $1-3$ or more, of which $1-2$ are healthy and the rest are rudimentary (Figure 2(a)) with six regular-sized stamens. Mature spikelets also showed single kernel in all rice genotypes and in O. rufipogon, whereas in Jugal, the number varies from 1 - 3 per grain with vary-

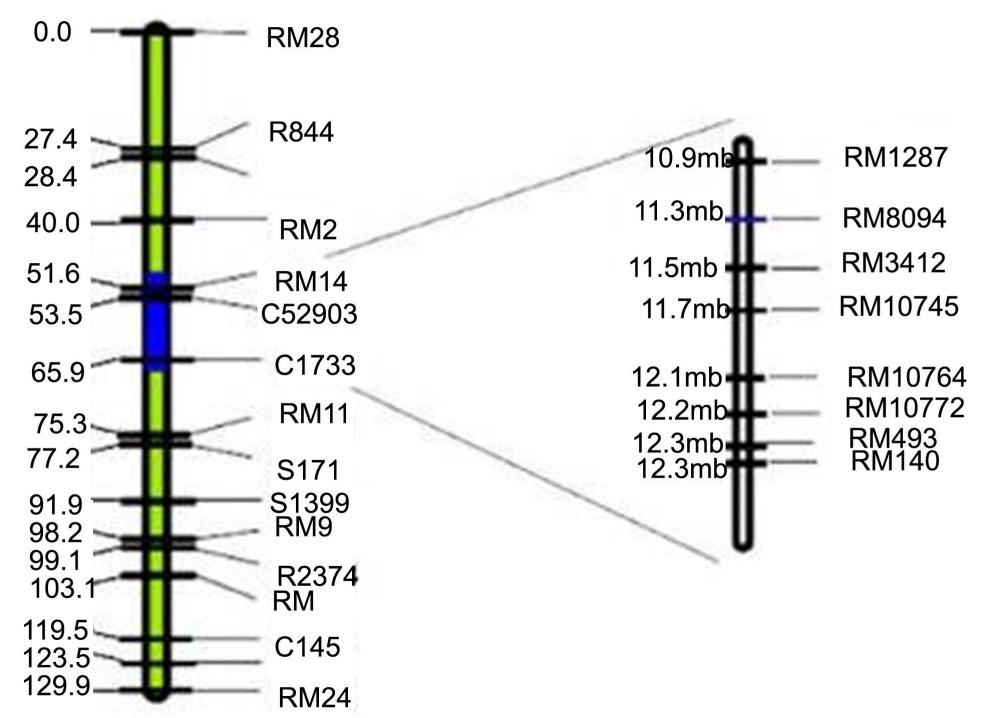

Figure 1. Location of the Saltol QTL on rice 1st chromosome with selected SSR loci use in this study (taken from Mohammadi-Nejad et al. 2008).

Table 4. Details of the used SSR used in present study.

\begin{tabular}{cccc}
\hline SSR loci & Motif & Forward sequence & Reverse sequence \\
\hline RM10745 & (TATG)9 & 5'TGACGAATTGACACACCGAGTACG3' & 5'ACTTCACCGTCGGCAACATGG3' \\
RM10764 & (AT)28 & 5'AGATGTCGCCTGATCTTGCATCG3' & 5'GATCGACCAGGTTGCATTAACAG3' \\
RM493 & (CTT)9 & 5'TAGCTCCAACAGGATCGACC3' & 5'GTACGTAAACGCGGAAGGTG3' \\
RM140 & (CT)12 & 5'TGCCTCTTCCCTGGCTCCCCTG3' & 5'GGCATGCCGAATGAAATGCATG3' \\
\hline
\end{tabular}


ing kernel size (Figure 2(b)). On germination the mature grains of Jugal produce variable number of young seedlings (Figure 2(c)).

Allelic diversity analysis for the selected floral organ development loci and SSR loci linked with Saltol QTLDNA amplification profile generated from the selected primer pairs were used to study the allelic diversity among the selected rice genotypes for floral organ development loci. The agarose gel picture showing amplification profile for the five loci (DL, FON4, OsMADS24, OsMADS45 and SPW1) are presented in Figure 3(a) and Figure 3(b). Based on the presence or absence of a specific allele among the selected genotypes, a dendrogram (Figure 4(a)) was constructed where Jugal showed its highest closeness with $O$. rufipogon (a wild rice species) and next to this with Bhutmoori (a traditional line) but maximum distance with IR 36 (a high yielding improved line). On the other hand, in SSR derived dendrogram (Figure 4(b)) all cultivated genotypes were grouped in a single cluster and the wild rice (O. rufipogon) got totally separated from the selected rice lines.

\section{Discussions}

The spikelet is the fundamental reproductive unit in cereals whose morphogenesis and development have profound influence on yield. In rice, the spikelet is a single floret, composed of a lemma and palea, which are considered as the first-whorl organs and enclose two lodicules (second whorl), six stamens (third whorl), and a carpel containing a single ovule (fourth whorl). From the detailed morphological study, it has shown that the multipistilate (presence of more than one pistil within a spikelet) trait is the unique genotype studied (cv. Jugal), which is a result of uncontrolled activity of reproductive meristems. In normal cultivated rice and in O. rufipo-

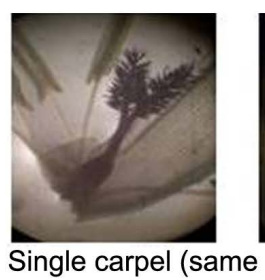

Single carpel (sam

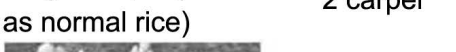

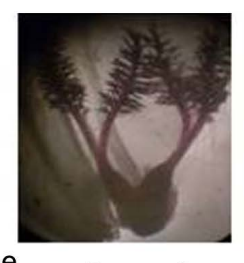

2 carpel

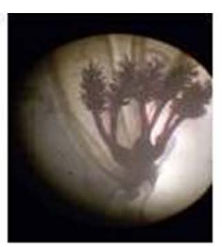

3 carpel

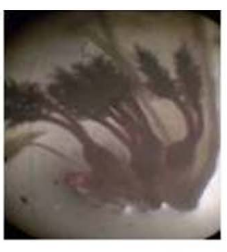

4 carpel

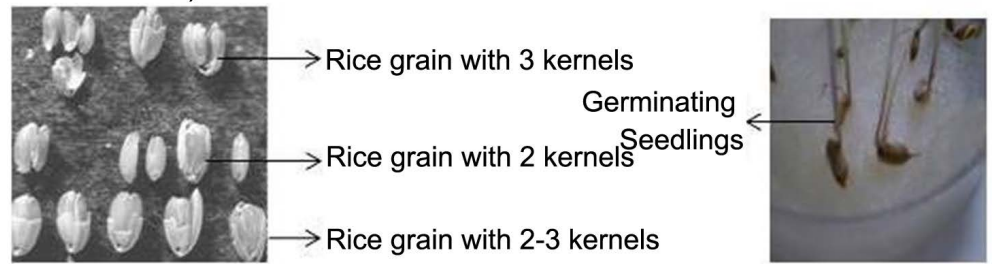

Figure 2. (a) Dissected Rice spikelet with single carpel and multiple carpels (in var. Jugal); (b) Grains with multiple kernels (Jugal); (c) Germinating rice grains with two seedlings (in var. Jugal).

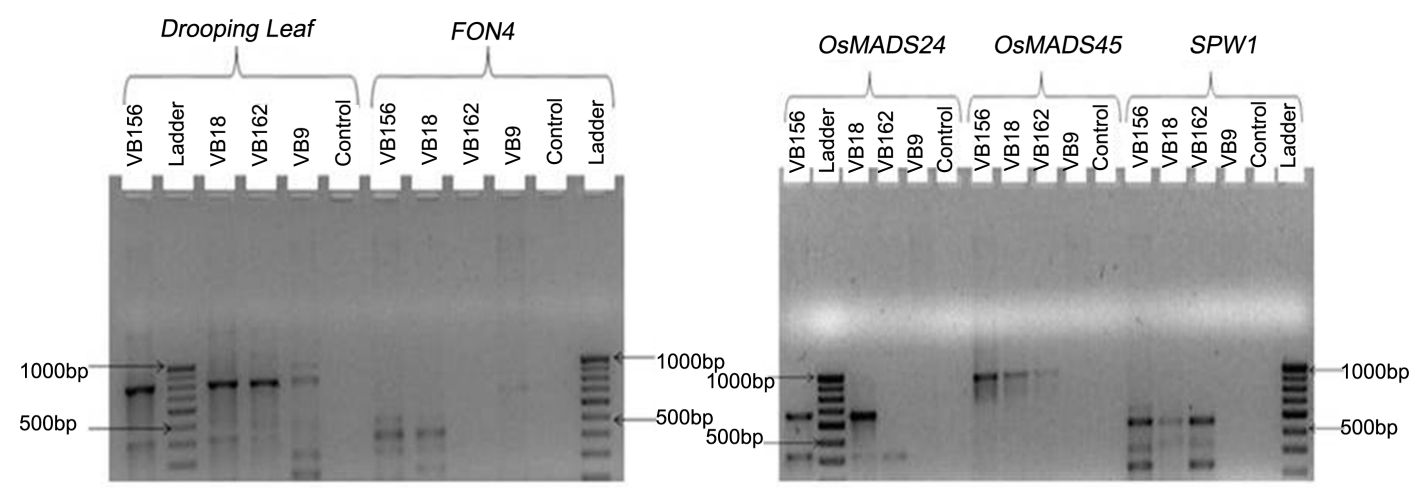

Figure 3. (a) (b) Gel picture showing amplified product the studied lines for the used floral organ development loci (DL, FON4, OsMADS24, OsMADS45 and SPW1) (The control lane contains only PCR master mix without genomic DNA) (VB156-Jugal, VB18-O. rufipogon, VB162-Bhut Moori, VB9-IR 36). 
Dendrogram using average linkage (Between Groups)

Rescaled distance cluster combined

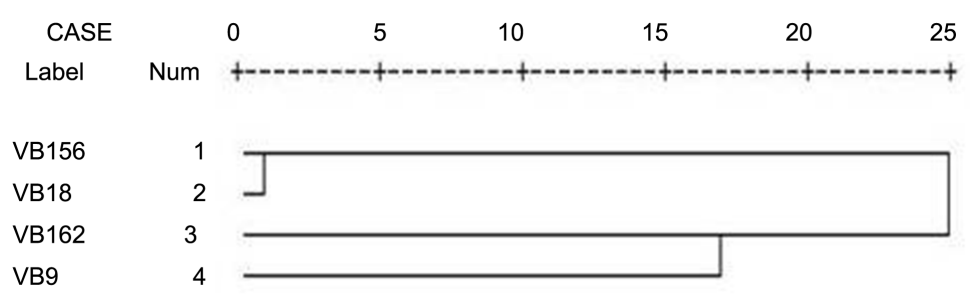

(a)

Dendrogram using average linkage (Between Groups)

Rescaled distance cluster combined

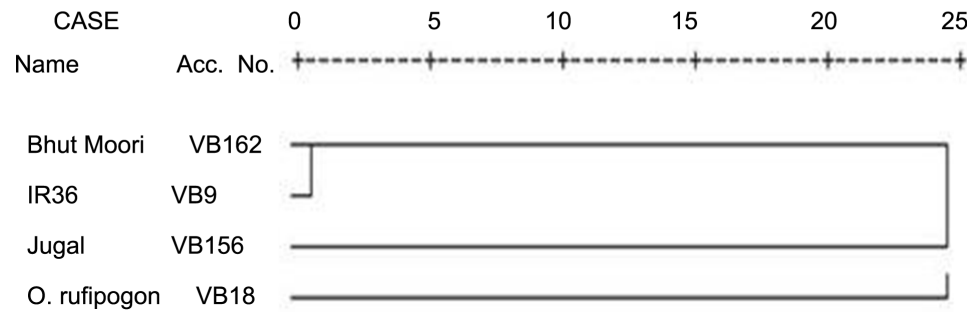

(b)

Figure 4. (a) Dendrogram derived from polymorphism screening for floral organ development loci; (b) Dendrogram derived from polymorphism screening for selected SSR loci.

gon, the meristematic activity in a spikelet stops after the production of the gynoecium, but in Jugal, the meristematic activity continues after fertilization, resulting in additional rudimentary pistil along with the mature normal one. But as the dimension is almost fixed for each spikelet, the mature kernels become reduced in size. The alternative structure (mutant form) of the rice spikelet is controlled by a number of homeotic genes, almost all of which are orthologous to a number of floral organ development loci of Arabidopsis.

This experiment constitutes a comparative analysis of a few selected genetic loci commonly associated with floral organ development and most importantly floral organ number in rice. For study of allelic diversity, the amplicon size for individual loci was taken as the clustering criteria where the mutant line showed uniqueness by being isolated from other lines. For further confirmation of this isolating nature, another set of molecular markers was employed which did not support the earlier clustering behavior. The prime limitation of this investigation is the use of allelic size (variation in mol. wt. of the amplified product for a locus) as the principal criterion for separation. For further confirmation, the amplified products need to be sequenced and bioinformatically analyzed. As there is no information available for this valuable mutant for its floral organ genetics, our study provides preliminary molecular information for undertaking further genomic analysis of the special trait of gynoecium replication.

\section{Acknowledgements}

Authors are thankful to Department of Science and Technology, Government of India for financial assistant (research grant No. SERB/F/208/2014-15).

\section{References}

[1] Khush, G. (2013) Strategies for Increasing the Yield Potential of Cereals: Case of Rice as an Example. Plant Breeding, 132, 433-436. http://dx.doi.org/10.1111/pbr.1991 
[2] Newton, A.C. (2009) Cereal Land Races for Sustainable Agriculture: A Review. Agronomy for Sustainable Development, 1, 33.

[3] Cleveland, D.A., Soleri, D. and Smith, S.E. (1994) Do Folk Crop Varieties Have a Role in Sustainable Agriculture? BioScience, 44, 740-751. http://dx.doi.org/10.2307/1312583

[4] Yesmin, N., Elias, S.E., Rahman, M.S., Haque, T., Mahbub Hasan, A.K.M. and Seraj, Z.I. (2014) Unique Genotypic Differences Discovered among Indigenous Bangladeshi Rice Landraces. International Journal of Genomics, 2014, Article ID: 210328. http://dx.doi.org/10.1155/2014/210328

[5] Parikh, M., Sharma, B., Chaudhari, P.R., Bhandarkar, S. and Sharma, D. (2014) Collection and Conservation of Extinct Land Races of Rice from Raigarh District of Chhattisgarh. Recent Research in Science and Technology, 6, 111-112.

[6] Karmakar, J., Roychowdhury, R., Kar, R.K., Deb, D. and Dey, N. (2012) Profiling of Selected Indigenous Rice (Oryza sativa L.) Landraces of Rarh Bengal in Relation to Osmotic Stress Tolerance. Physiology and Molecular Biology of Plants, 18, 125-132. http://dx.doi.org/10.1007/s12298-012-0110-1

[7] Ganie, S.A., Karmakar, J., Roychowdhury, R., Mondal, T.K. and Dey, N. (2014) Assessment of Genetic Diversity in Salt-Tolerant Rice and Its Wild Relatives for Ten SSR Loci and One Allele Mining Primer of salT Gene Located on 1st Chromosome, Plant Systematics and Evolution. Plant Systematics and Evolution, 300, 1741-1747. http://dx.doi.org/10.1007/s00606-014-0999-7

[8] Biswas, T. and Bhattacharya, S. (2013) Microsatellite Marker Based Diversity Analysis for Drought Tolerance in Some Bengal Landraces of Rice (Oryza sativa L.). Indian Journal of Agricultural Research, 47, 431-435.

[9] Ram, G.S., Thiruvengadam, V. and Vinod, K.K. (2007) Genetic Diversity among Cultivars, Landraces and Wild Relatives of Rice as Revealed by Microsatellite Markers. Journal of Applied Genetics, 48, 337-345. http://dx.doi.org/10.1007/BF03195230

[10] Deb, D. (2005) Seeds of Tradition, Seeds of Future: Folk Rice Varieties of Eastern India. RFSTE, New Delhi.

[11] Deb, D. and Bhattacharya, D. (2009) Two Unique Landraces from West Bengal. Seed Research, 37, 152-155.

[12] Prain, D. (1903) Bengal Plants. Vol. 2, Botanical Survey of India, Calcutta, 1184.

[13] Pandian, R.T. and Thiyagarajan, K. (2004) Inheritance of Floral Traits in Spontaneous Mutant in Rice (Oryza sativa L.). Current Science, 87, 1051-1052.

[14] Morinaga, T. and Jajiri, T. (1941) The Inheritance of Polycaryoptic Rice, with Special Reference to the Germination Structure of the Lemma. The Japanese Journal of Genetics, 17, 57-62. http://dx.doi.org/10.1266/jjg.17.57

[15] Kasahara, Y. (1944) On the Characters of a Partially Two Chamber Ovary of Rice Plant and Its Heredity. Japanese Journal of Crop Science, 16, 54-57. http://dx.doi.org/10.1626/jcs.16.3-4 54

[16] Heu, M.H. and Su, S.H. (1976) The Inheritance of Poly-Caryopsis and Its Linkage Relations in Rice. Korean Journal of Breeding Science, 8, 147-152.

[17] Heu, M.H., Nam, Y.W. and Suh, H.S. (1987) Inheritance of Multiple Pistil Character Derived from "Double Rice". Korean Journal of Breeding Science, 19, 404-409.

[18] Huang, H. and Ma, H. (1997) FON1, an Arabidopsis Gene That Terminates Floral Meristem Activity and Controls Flower Organ Number. Plant Cell, 9, 115-134.

[19] Huang, H. and Ma, H. (1998) The Nature of the Arabidopsis fon1 Mutations. Plant Cell, 10, 3-4. http://dx.doi.org/10.1105/tpc.10.1.3

[20] Chu, H., Qian, Q., Liang, W., Yin, C., Tan, H., Yao, Y., Yuan, Z., Yang, J., Huang, H., Luo, D., Ma, H. and Zhang, D. (2006) The FLORAL ORGAN NUMBER4 Gene Encoding a Putative Ortholog of Arabidopsis CLAVATA3 Regulates Apical Meristem Size in Rice. Plant Physiology, 142, 1039-1052. http://dx.doi.org/10.1104/pp.106.086736

[21] Yamaguchi, T., Nagasawa, N., Kawasaki, S., Matsuoka, M., Nagato, Y. and Hirano, H.-Y. (2004) The YABBY Gene DROOPING LEAF Regulates Carpel Specification and Midrib Development in Oryza sativa. Plant Cell, 16, 500-509. http://dx.doi.org/10.1105/tpc.018044

[22] Ambrose, B.A., Lerner, D., Ciceri, R.P., Padilla, C.M., Yanofsky, M.F. and Schmidt, R.J. (2000) Molecular and Genetic Analysis of the Silky1 Gene Reveals Conservation in Floral Organ Specification between Eudicots and Monocots. Molecular Cell, 5, 569-579. http://dx.doi.org/10.1016/S1097-2765(00)80450-5

[23] Nagasawa, N., Miyoshi, M., Sano, Y., Satoh, H., Hirano, H., Sakai, H. and Nagato, Y. (2003) SUPERWOMAN1 and DROOPING LEAF Genes Control Floral Organ Identity in Rice. Development, 130, 705-718. http://dx.doi.org/10.1242/dev.00294

[24] Arora, R., Agarwal, P., Ray, S., Singh, A.K., Singh, V.P., Tyagi, A.K. and Kapoor, S. (2007) MADS-Box Gene Family in Rice: Genome-Wide Identification, Organization and Expression Profiling during Reproductive Development and Stress. BMC Genomics, 8, 242. 
[25] Xu, G.X. and Kong, H.Z. (2007) Duplication and Divergence of Floral MADS-Box Genes in Grasses: Evidence for the Generation and Modification of Novel Regulators. Journal of Integrative Plant Biology, 49, 927-939. http://dx.doi.org/10.1111/j.1744-7909.2007.00502.x

[26] Ma, H., Yanofsky, M.F. and Meyerowitz, E.M. (1991) AGL1-AGL6, an Arabidopsis Gene Family with Similarity to Floral Homeotic and Transcription Factor Genes. Genes \& Development, 5, 484-495. http://dx.doi.org/10.1101/gad.5.3.484

[27] Temnykh, S., DeClerck, G., Lukashova, A., Lipovich, L., Cartinhour, S. and McCouch, S. (2001) Computational and Experimental Analysis of Microsatellites in Rice (Oryza sativa L.): Frequency, Length Variation, Transposon Associations, and Genetic Marker Potential. Genome Research, 11, 1441-1452. http://dx.doi.org/10.1101/gr.184001

[28] Bonilla, P.S., Dvorak, J., Mackill, D., Deal, K. and Gregorio, G. (2002) RFLP and SSLP Mapping of Salinity Tolerance Genes in Chromosome 1 of Rice (Oryza sativa L.) Using Recombinant Inbred Lines. The Philippine Agricultural Scientist, 85, 64-76.

[29] Mohammadi-Nejad, G., Arzani, A., Rezai, A.M., Singh, R.K. and Gregorio, G.B. (2008) Assessment of Rice Genotypes for Salt Tolerance Using Microsatellite Markers Associated with the Saltol QTL. African Journal of Biotechnology, 7, 730-736.

[30] Mohammadi-Nejad, G., Singh, R.K., Arzani, A., Rezaie, A.M., Sabouri, H. and Gregorio, G.B. (2010) Evaluation of Salinity Tolerance in Rice (Oryza sativa L.) Genotypes. International Journal of Plant Production, 4, 199-208. 